\title{
Isometric Neck Exercises versus Dynamic Neck Exercises in Chronic Neck Pain
}

\author{
Sowmya M.V, M.P.T [Ortho] \\ Assistant Professor, Department of Orthopedic physiotherapy \\ Meenakshi College of Physiotherapy, Chennai, India.
}

\section{Introduction}

Neck disorders remain a common problem in modern industrialized countries. Neck pain has been the most common chief complaint among working aged men and women ${ }^{29,38}$. Kasch H, Bach FW, StengaardPedersen K, Jensen TS, Devereaux MW, Phero JC, neck pain may originate from any of the structures in the neck. These include muscles and nerves as well as the spine and the cushioning discs in between. Neck pain may also come from regions near the neck, like the shoulder, jaw, head, and upper arms. When your neck is sore, you may have difficulty moving it, especially to one side. Many people describe this as having a stiff neck $^{13,26,32}$.

If neck pain involves nerves (for example, significant muscle spasm pinching on a nerve or a slipped disc compressing a nerve), you may feel numbness, tingling, or weakness in your arm, hand, or elsewhere ${ }^{13,26,32}$. A common cause of neck pain is muscle strain or tension ${ }^{13,26,32}$. Florence Peterson Kendall, Elizabeth Kendall Mc Corney, Patricia Giece Provance in their publication say that the muscle problems associated with pain in the posterior neck are essentially of two types, one associated with muscle tightness and the other with muscle strain. Symptoms and treatment indications differ according to the underlying fault. Both types are quite prevalent; the one associated with muscle tightness usually has a gradual onset of symptoms, while the one associated with muscle strain usually has an acute onset ${ }^{15}$.

Usually, everyday activities are to blame. Such activities include bending over a desk for hours, having poor posture while watching TV or reading, placing your computer monitor too high or too low, sleeping in an uncomfortable position, or twisting and turning the neck in a jarring manner while exercising. Traumatic accidents or falls can cause severe neck injuries like vertebral fractures, whiplash injury, blood vessel injury, and even paralysis. Other causes include herniated disc, fibromyalgia (pain syndrome throughout the body), and arthritis. Meningitis, although much less common, can cause significant neck stiffness ${ }^{13,26,32}$.

Davies, GJ Hislop, HJ Lehmukuhl, LD and Smith LK says that Isometric exercise is a static form of exercise that occurs when a muscle contracts without an appreciable change in the length of the muscle or without visible joint motion ${ }^{12,21,27}$. If adaptive changes in muscle, such as increase in strength and endurance, are to occur, isometric contractions should be held against resistance for at least 6 seconds $^{9,28}$. This allows time for peak tension to develop and for metabolic changes to begin to occur in the muscle with each contraction ${ }^{9,16}$.

Carrie M.Hall, Lori Thein Brody says that isometric exercise is commonly used to increase muscle performance. Although no joint movement occurs, isometric exercise is considered functional because it provides a strength base for dynamic exercise and because many postural muscles work primarily in an isometric fashion. Isometric exercise is used as a special technique in proprioceptive neuromuscular facilitation to improve the endurance and strengthens the muscles in a weak portion of the range. Isometric exercise is most effective when individuals are in a low state of training, because the benefits of isometric exercise decrease as a state of training increases ${ }^{8}$.

Gary Kannen in his publication tells that in contrast to isometric exercise, dynamic resistance exercise involves movement. These muscle contractions involve changes in muscle length and joint angles. One of the best-known legends involving dynamic resistance exercise and the overload principle was written about $500 \mathrm{BC}^{17}$. Carrie M.Hall, Lori Thein Brody in their text published that dynamic muscle strengthening occurs when muscles contract as they shorten (i.e., concentric contractions) or lengthen (i.e., eccentric contractions); resulting in movement of the joint they cross. The advantages of dynamic exercise include increased movement of the joint, resulting in maintenance of capsular, ligament, and muscular flexibility and increased in cartilage nutrition. Muscle strengthening occurs in the entire joint ranges achieved during the exercise and results in a functionally more efficient muscle-joint complex ${ }^{8}$.

\section{Need And Significance Of Study:}

Aker PD, Gross AR, Goldsmith CH, Peloso P mentioned that evidence for many of the standard treatment approaches to neck pain is lacking. Conservative management of neck disorders includes both passive and active therapies neither of which have been shown to be effective ${ }^{1}$. Rush PJ, Shore A says however these 
treatments are widely prescribed by physicians ${ }^{39}$. Although dynamic neck exercises and its advantages has been proven to be effective method of treatment in neck pain patients, not much studies have come in support of this. The need of my study was to investigate the efficacy of isometric neck strengthening exercises and dynamic neck strengthening exercises by comparing both and also to see if dynamic neck exercises could be a better treatment method than that of isometric neck exercises.

\section{OBJECTIVES OF STUDY:}

The objective of my study is to evaluate the efficacy of isometric neck strengthening exercises and dynamic neck strengthening exercises and comparing both in the treatment of patients with chronic neck pain.

\section{HYPOTHESIS:}

\section{NULL HYPOTHESIS [H0]:}

There will be no significant difference between dynamic neck exercises to isometric neck exercises in the treatment of chronic pain.

\section{EXPERIMENTAL HYPOTHESIS [H1]:}

There will be a significant difference seen in dynamic neck exercises to isometric neck exercises in the treatment of chronic neck pain.

\section{Review of Literature}

- Falla D et al [2006]- Suggested that an endurance strength exercise regime for cervical flexor muscles is effective in reducing myoelectric manifestations of superficial cervical flexor muscle fatigue as well as increasing cervical flexion strength in a group of patients with chronic non-severe neck pain.

- O'Leary S et al [2006]- Conducted a study on the impairment of the cranio-cervical flexor muscles is a feature of painful cervical spine disorders. The aim of this study was to investigate if cranio-cervical flexor muscle impairment is present over a range of contraction intensities in neck pain sufferers compared to normal people.46 patients with neck pain and 47 control participants were taken up for this study. Neck pain participants demonstrated poor accuracy in maintaining their maximum voluntary contraction at the nominated isometric cranio-cervical flexor torque amplitude.

- Ayman Ali Gallom et al [2005]-Suggested that the symptoms of cervical spondylosis may appear in those as young age as 30 years and more commonly in those aged 40-60years.Morbidity ranges from chronic neck pain, radicular pain, diminished range of motion, headache, weakness and impaired fine motor coordination. Both sexes are affected equally. When cervical spondylosis develops in young individuals it is almost always secondary to a predisposing abnormality in one of the joints between cervical vertebras probably as a result of previous mild trauma. Isometric exercises often are beneficial to maintain the strength of neck muscles.

- Burnett AF et al [2005]- This study suggested that strength training might be an effective means to strengthen the neck and decrease injury risk. The cohort consisted of 32 aged height-weight matched participants divided into two experimental groups, multi cervical unit and theraband tubing groups and a control group. Results demonstrated that multi cervical unit was most effective training modality to increase isometric cervical muscle strength. Theraband did however produce moderate gains in isometric neck strength.

- Dvora shurman et al [2005]-Published in their article that though muscle loss happens to everyone , regular exercise develops a reservoir of muscle to call upon. We use elastic bands and balls to enhance certain exercises. For example pulling an elastic band while doing arm activation or cross crawl, turns these movements into strength training.

- Folland JP et al [2005]-Demonstrated in their study that strength training with isometric contraction produces large but highly angle specific adaptations. 33 active healthy males 18-30 years completed 9 weeks of strength training of quadriceps muscle group 3 times per week. To contrast the contractile mode of isometric versus dynamic training, but diminish the strong angle specificity effect, we compared the strength gains produced by isometric training at for joint angles with conventional dynamic training. Isometric strength increases were significantly greater for isometrically trained leg.

- Kay TM, Gross A et al [2005]- Selected studies were randomized and investigated the use of exercise therapy as a treatment in adults with mechanical neck disorders with or without headache. There is a moderate evidence of benefit that neck strengthening exercises reduce pain, improve function and global perceived effect for chronic neck disorder with headache in the short and long term.

- Lee $\mathbf{H}$ et al [2005]-To investigate associations between categories of response to neck pain/discomfort and (1) the endurance time of neck muscles, neck range of motion, and neck and head morphology, (2) sensitization or stretch effects arising from repeating end-of-range measurements, and (3) self-report data 
from neck pain and disability questionnaires. The affective dimension of Neck Disability Index scores were significantly higher by subjects who had sought treatment than those of the untreated groups.

- Mansell J et al [2005]- Performed their study on 36 collegiate soccer players who underwent an 8-week cervical resistance-training program that consisted of 3 sets of 10 repetitions of neck flexion and extension at $55 \%$ to $\& 70 \%$ of 10 repetitions maximum two times a week. Despite increases in isometric strength and girth, the 8-week isotonic cervical resistance training did not enhance head-neck segment dynamic stabilization during force application in collegiate soccer players.

- Shawn Kwak, DPT et al [2005]- The purpose of this study was to investigate the relationship between measured active cervical ROM and perceived neck disability, as measured by the NDI.23 senior center attendees aged 60 to 90 participated. Their range of motion of cervical region was measured using an instrument and neck disability was characterized using Neck Disability Index. Pearson correlation was used to describe the relation between both. There was an inverse relation between cervical range of motion and neck disability scores that is as range of motion decreased, neck disability index scores increased.

- Brain R.Mulligan [2004]- Vertebral artery signs are a contraindication to manipulation and movements of the neck. Neck movements especially neck extension commonly causes giddiness. However rotation and flexion can also be a problem.

- Devereaux MW [2004], KaschH et al [2003], Phero JC [2003]- A common cause of neck pain is muscle strain or tension. Usually, everyday activities are to blame. Such activities include bending over a desk for hours, having poor posture while watching TV or reading, placing your computer monitor too high or too low, sleeping in an uncomfortable position, or twisting and turning the neck in a jarring manner while exercising. Traumatic accidents or falls can cause severe neck injuries like vertebral fractures, whiplash, blood vessel injury, and even paralysis. Other causes include herniated disc, fibromyalgia (pain syndrome throughout the body), and arthritis. Meningitis, although much less common, can cause significant neck stiffness.

- Thomas T.W et al [2004]- This study was done to evaluate the efficacy of neck exercise program in patients with chronic neck pain.145 patients were randomly allocated into an exercise of dynamic strengthening of neck muscles for 6 weeks and non exercise group was given infra red radiation. After 6 weeks patients with chronic neck pain can benefit from the neck exercise program with significant improvement in disability, pain, and isometric neck muscle strength in different directions.

- Jari Ylinen MD et al [2003]- Their study was done to evaluate the efficacy of intensive isometric neck strength training and lighter endurance training of neck muscles on pain and disability in women with chronic, non specific neck pain. 180 female office workers between ages of 25 and 53 years with chronic, nonspecific neck pain. Patients were randomly assigned to 2 training groups of dynamic neck exercises (endurance) and high intensity isometric neck strengthening (strength) exercises with an elastic band for 12 month follow up. The results showed that both strength and endurance training for 12 months was effective method for decreasing pain and disability in women with chronic, non specific neck pain

- Sarig H Bahat [2003]- Systematic review was to determine if various exercise methods are effective in treating different mechanical neck disorders occurring in adults.16 trials were included. Findings revealed relatively strong evidence supporting the effectiveness of proprioceptive exercises and dynamic resisted strengthening exercises of the neck shoulder musculature for chronic or frequent neck disorders.

- Viljanen M et al [2003]- Mean age of 45years with chronic non specific neck pain were randomly assigned to 12 weeks of dynamic muscle training. Dynamic muscle training did not lead to better improvements in neck pain compared with ordinary activity.

- Aromaa A et al [2002]- Demonstrated in their study that the prevalence of chronic neck pain has been reported to be 7\% in women and 5\% in men. Patients with chronic neck pain used health care services twice as much as the population on average.

- David J.Magee [2002]-Published in his book that the criteria to classify stages of injury are as follows. Generally acute conditions are those that have been present for 7 to 10 days. Subacute conditions have been present for 10 days to 7 weeks, and chronic conditions or symptoms have been present for longer than 7 weeks.

- Ahlgren C et al [2001]-Demonstrated that their study by performing on 102 women with trapezius myalgia were randomized to strength,endurance,coordination andnon-training groups. The results indicate that regular exercises with strength, endurance or coordination training of neck/shoulder muscles might alleviate pain for women with work related trapezius myalgia.

- Hakkien et al [2001]- Demonstrated that in a randomized 2year study of dynamic strength training in individuals with early rheumatoid arthritis, subjects performed strength training exercises with elastic bands and were instructed to exercise twice weekly at moderate load levels, performing 2 sets of each exercise 
with 12-18 repetitions per set. Results indicate that minimally supervised, at home strength training led to significant increases in muscle strength and physical functioning.

- Leon Chaetow [2001]- Suggested that the length of time the effort is held for 7-10 seconds or more or less (Lewit (1999) favours 7 seconds; Greenman (1989), Goodridge \&Kuchera (1997) all favours 3 seconds. The number of times the isometric contraction (or its variant) is repeated-3 repetitions are thought to be optimal( Goodridge \& Kuchera 1997).

- Portero P et al [2001]- Purpose of this study was to quantify the neuromuscular cervical adaptations to an 8-week strength training program.70 healthy men with no pathological conditions of neck performed a lateral flexion, isometric-resistance training program 3 times a week. The results indicate that beneficial effect of a strength-training program, which increases neck muscle size and strength during lateral flexion, and decreases the fatigability of the superficial muscles of the neck.

- SusanB.O'Sullaivan et al [2001]- Different protocols using isometric, concentric and eccentric contractions have been developed. Purposes, isometric frequency 5-10 repetitions daily and dynamic frequency 2-3 times/week on alternate days. Physical therapy is not appropriate for unstable vestibular disorders.

- Helen J.Histop et al [1999]- Despite the multiple issues and problems with manual muscle testing, both reliability and validity are satisfactory for clinical use and can never be "perfect" because of the subjectivity of the measures.

- Jordan A et al [1999]- Study was done to determine the maximal isometric strength of the flexors and extensors and of the cervical musculature in 100 healthy volunteers (50 men and 50 women). Testing was carried out using strain gauge technology on a neck muscle training apparatus. Successful rehabilitation of cervical musculature will require considerable resistance for sufficient stimulation of cervical musculature.

- Jette AM et al, [1999], Mikesky AE et al.[1994], Topp.et al[2002]-Suggested in the theraband instruction manual that the theraband elastic resistance has been proven to increase strength, mobility and function as well as reduce joint pain. Yellow colour theraband has a thin resistance level that is prescribed for beginner's workout level.

- Ylinen JJ et al [1999]- Study was done to evaluate the repeatability of advanced method of measuring the strength of functionally different groups of neck muscles using isometric apparatus. Statistics shows that chronic neck pain has been associated with poor isometric neck strength. In rehabilitation, strength measurements may thus help to evaluate basic condition and show whether or not treatments and exercises have been beneficial for improving strength.

- Randlov A et al [1998]- Female patients aged 18-65 years suffering from chronic neck/shoulder pain for a minimum of six months. The type of low-tech dynamic training used in either of our two programs resulted in both subjective and objective improvements in patients suffering from chronic neck/shoulder pain, but there were no statistically significant differences in outcome between two approaches.

- $\quad$ Richard E Baxter [1998]- Suggested that cervical spondylosis treatment options are cervical isometrics (pain free), VA-basilar artery insufficiencies see for the signs and symptoms and refer the patient for medical diagnosis.

- Ann Thomson et al [1996]- Suggested that in vertebrobasilar insufficiency rotation\&lateral flexion should not be used. This insufficiency is indicated if this makes the patient dizzy. Occlusion of the vertebral artery can therefore give rise to impairment of balance and vision.

- Carolyn Kisner MS, PT et al [1996], Cummings GS et al [1992] - In the treatment considerations of chronic stage -return to function phase, progression of sub maximal-to-maximal resistance, specificity of exercise using resisted concentric and eccentric are used.

Contraindications during the active inflammatory period-Maximum resistive exercise should not be performed. Even though muscles tend to weaken, vigorous strengthening exercises will cause join compression and increase the irritability of the joint, potentially increasing damage to the joint surfaces.

In the treatment considerations for osteoarthritis, precautions are maximum resistance exercise should not be performed through that range of motion where stress is being placed.

Inappropriate movements of the spine could be life threatening or extremely debilitating because of the potential of subluxations and dislocations to cause damage to the cervical cord or vertebral artery in rheumatoid arthritis. If a patient has rheumatoid arthritis traction or joint mobilizations in the spine are potentially dangerous because of ligamentous necrosis and vertebral instability and therefore contraindicated.In tension headache management has to be to evaluate the flexibility and strength of the muscles in the cervical, upper thoracic, and shoulder girdle, and design an exercise program to regain a balance in length and strength in preparation for posture correction and training.

- Berg $\mathbf{H}$ et al [1994]- This study examined whether neck resistance training could increase strength and reduce pain in workers with a high prevalence of neck disorders. Middle aged women workers exercised 
twice weekly for a period of 8 weeks of resisted rotation, flexion, extension. This suggested that 12 weeks of specific neck strength training twice weekly for 8 weeks increases the strength of muscles of neck.

- Ylinen, Ruuska J [1994]- The purpose of this study was to evaluate isomeric strength of neck flexor and extensor muscles in 56 patients with neck and shoulder pain. An isometric measurement protocol was performed at the beginning and at the end of a 3-week rehabilitation program that included physiotherapy, stretching, aerobics exercises, and circuit training to improve arm, shoulder, and neck muscle strength. There was a significant increase in ability to push forward and backward which correlated with lessening of neck pain and disability found at the end of the program.

- Florence Peterson Kendall et al [1993]-The muscle problems associated with pain in the posterior neck are essentially of two types, one associated with muscle tightness and the other with muscle strain. Symptoms and treatment indications differ according to the underlying fault. Both type are quite prevalent; the one associated with muscle tightness usually has a gradual onset of symptoms, while the one associated with muscle strain has an acute onset.

- Pollock ML et al [1993]- Their study consisted of 50 men and 28 women and was assigned to one of the four training groups or control groups. Training group exercised for 12 weeks as follows; once per week using one set of dynamic exercise, once per week using one set of dynamic set of maximal isometric exercise at eight angles through a 126 degrees- range of cervical extension. Done to evaluate the effect of frequency and volume of resistance training on cervical extension strength. A greater increase in strength was found when the groups that trained 2 times a week were compared to those that trained once per week.

- Howard Vernon, DC [1991]-Gave that the Neck Disability Index has become a standard instrument for measuring self rated disability due to neck pain and is used by clinicians and researchers alike. Scoring intervals for interpretations as follow's-0-4=no disdbility, 5-14=mild, 15-24=moderate, 25-34=severe, above $34=$ complete.

- Vernon H, Mior S [1991]-A modification of Oswestry Low back Pain Index was conducted producing a 10 item scaled questionnaire entitled the Neck Disability Index (NDI). This index was used for scoring the disability and pain in patients suffering from neck disorders either specific or non-specific pain.

- Harris\&Watkins [1990]- said that the use of elastic resistance bands through a range of motion may be adequate in case of elderly patients who is recovering from a hip fracture and whose goal is walking and light housekeeping. Such a program would enable the patient to do what he needs to do, and would also be easy to continue at a maintenance level at home.

- Schuldt K et al [1988]-In order to analyze isometric muscle test contractions in neck and shoulder region an electromyography (EMG) study of 10 healthy females was undertaken. A series of 13 standardized isometric contractions with manual resistance was performed in the sitting position. Maximum level of activity was obtained in neck extension, lateral flexion, and abduction of arm in the plane of scapula.

- Fox E and Mathews D [1981]- Said that if adaptive changes in muscle, such as increase in strength and endurance are to occur, isometric contractions should be held against resistance for at least 6 seconds. This allows time for peak tension to develop and for metabolic changes to begin to occur in the muscle with each contraction.

- Carrie M Hall et al [1980]-Isometric exercise is commonly used to increase muscle performance. Although no joint movement occurs, isometric exercise is considered functional because it provides us strength base for dynamic exercise and because many postural muscles work primarily in an isometric fashion. Isometric exercises are used as a special technique in proprioceptive neuromuscular facilitation to enhance stability and strengthen muscles in a weak portion of the range. Isometric exercise is most effective when individuals are in a low state of training, because the benefits of isometric exercise decrease as the state of training increases. Use caution when prescribing isometric exercises for patients with hypertension or known cardiac disease.

Body weight, resistive bands, free weights, pulleys and weight machines are a few modes of dynamic resistive exercise.

In general start with low enough weight to allow approximately three sets of 10 repetitions.

Dynamic muscle strengthening occurs when muscles contract as they shorten (i.e., concentric contractions) or lengthen (i.e., eccentric contractions), resulting in movement of the joint they cross. The advantages of dynamic exercise include increased movement of the joint, resulting in maintenance of capsular, ligament, and muscular flexibility and increased cartilage nutrition. Muscle strengthening occurs in all joint ranges achieved during the exercise and results in a functionally more efficient muscle joint complex.

- GaryKannen [1979]- Suggested that in contrast to isometric exercise, dynamic resistance exercise involves movement. These muscle contractions involve changes in muscle length and joint angles. One of the best known legends involving dynamic resistance exercise and the overload principle was written about 500BC.Practically any stimulus that provides a moderate or high level of muscle force repeated regularly increases muscle strength. 
- Zohn D, andMannell J [1976]- Dynamic resistance exercises are not indicated when a muscle or joint is inflamed or swollen. If a patient experience severe or muscle pain during exercise or for more than 24hours after exercise, the activity should be either eliminated or substantially reduced. If movement causes increased pain or increased inflammation, it is either too great a dosage or it should not be done.

- STUDY DESIGN

- STUDY SETTING

- SAMPLE SIZE AND METHOD OF SAMPLING

- SAMPLING CRITERIA:

INCLUSION CRITERIA:

- $\quad$ Age group 25-60 years - $^{4,9,36}$

- Both Males and Females ${ }^{43}$

- $\quad$ Patients with chronic stage neck pain (above 7 weeks) ${ }^{11}$

- Patients with Neck Disability Index (NDI) score above $15 / 50^{11,22}$

- Cervical spondylosis ${ }^{4,37}$

- Chronic stages of tissue healing ${ }^{9}$

- $\quad$ Tension headache ${ }^{9}$

\section{EXCLUSION CRITERIA:}

- Patients with less than 14/50 on Neck Disability Index (NDI) score ${ }^{11,22}$

- Acute pain \& inflammation ${ }^{9,10}$

- Acute inflammatory period in rheumatoid arthritis ${ }^{9,23}$

- Torticollis ${ }^{9,37}$

- Unstable/acute osteoarthritis ${ }^{23}$

- $\quad$ Recent fractures ${ }^{48}$

- Vertigo $2,6,40$

- Vertebrobasilar insufficiency ${ }^{2,37}$

- Chronic heart disease, Myocardial infarction ${ }^{23,39}$

- Pregnancy $^{34}$

- TOOLS OR APPARATUS REQUIRED:

- $\quad$ Neck Disability Index (NDI) ${ }^{22,47}$

- $\quad$ Elastic resistance band (Theraband -Yellow in colour) ${ }^{14,25,30,44,45}$

- Manual Muscle Testing (MMT) $)^{20,39}$

\section{- OUTCOME MEASURES:}

- Pain and Disability

- Muscle Power

\section{- PROCEDURE:}

A written informed consent was received from sixty patients suffering from chronic neck pain. The study was performed by assigning thirty patients from a group of sixty to either of the two training groups, namely the isometric neck exercises and the dynamic neck exercises groups. Pre test measurements were taken with the help of Neck Disability Index (NDI) scores and using manual muscle testing (MMT) prior to the intervention of neck strengthening exercises ${ }^{20,22}$.

One group of thirty patients performed dynamic neck exercises which included lifting head up with the chin tucked in from supine lying for neck flexion, lifting head backwards in prone lying for neck extension, lifting head sideways from pillow in side lying position for neck side flexion which is also repeated for the other side and finally lifting head off from the bed and rotating to one side for neck rotation, repeating both ways ${ }^{11}$. These exercises were performed for 8-10 repetitions for duration of three times a week on alternate days ${ }^{40}$.

The other group of thirty patients performed neck isometric exercises with an elastic resistance band (Theraband-Yellow in colour) ${ }^{30,44}$. Here the exercises were performed in sitting position, by holding the theraband directly forwards for neck flexion, backwards for neck extension and obliquely towards right and left 
and by crossing over the band for neck side flexion and rotation ${ }^{25,44,45}$. All these were done for about 5-10 repetitions with a hold time of 6 seconds ${ }^{39}$ at $75 \%$ of elongation with 1.1 Kilogram resistance offered by the theraband ${ }^{19,25,30,44,45}$.

Both the neck strengthening groups performed the above-mentioned exercises 3 times a week for a period of 3 weeks $^{49}$. Once the training was over, posttest measurements were taken from both the groups using Neck Disability Index (NDI) score and Manual Muscle Testing (MMT) ${ }^{20,22}$. Finally these values were tabulated accordingly.

\section{DYNAMIC NECK EXERCISES \\ CERVICAL FLEXION}

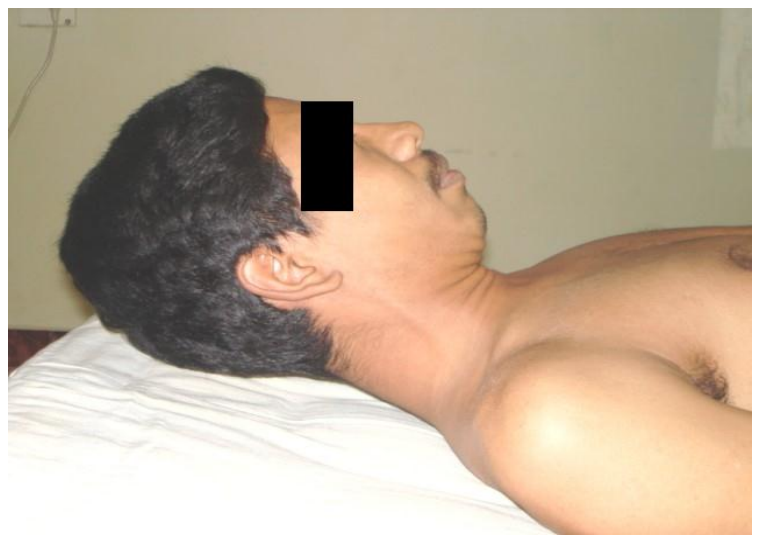

\section{CERVICAL EXTENSION}

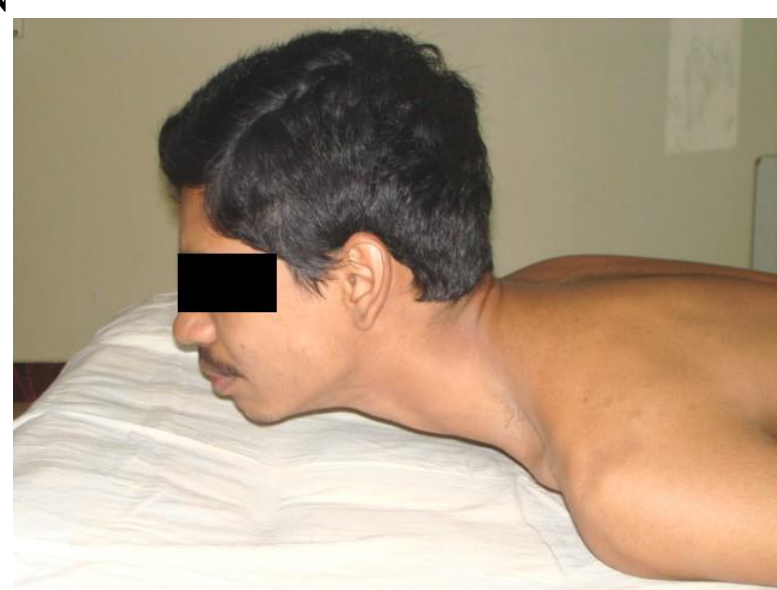

\section{CERVICAL SIDE FLEXION - RIGHT}

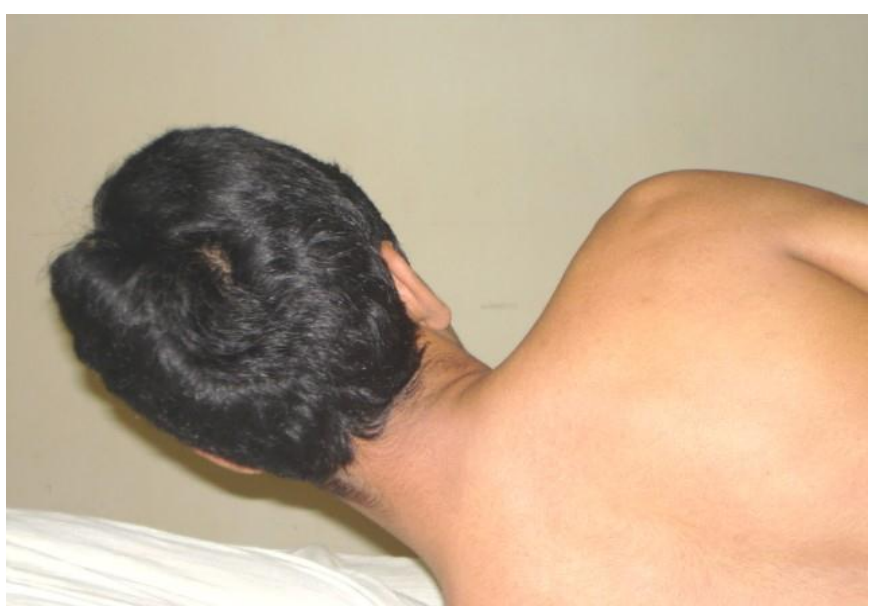




\section{CERVICAL ROTATION - LEFT}

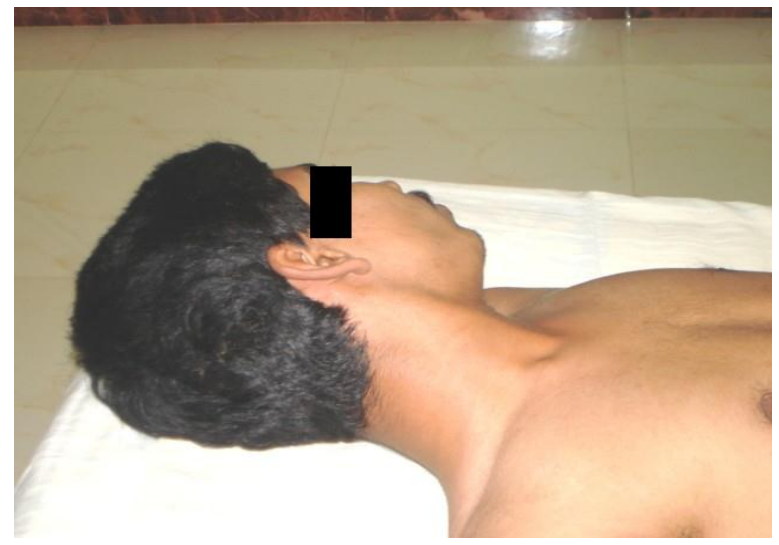

ISOMETRIC NECK EXERCISES

CERVICAL FLEXION

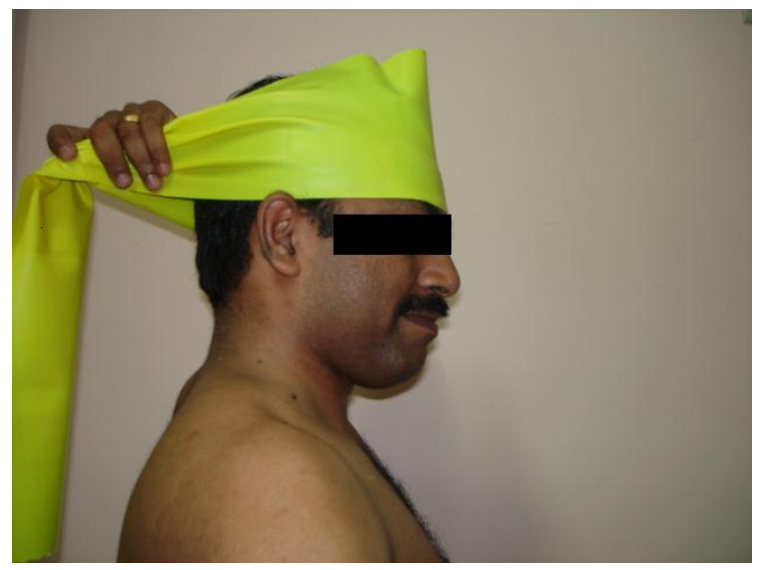

\section{CERVICAL EXTENSION}

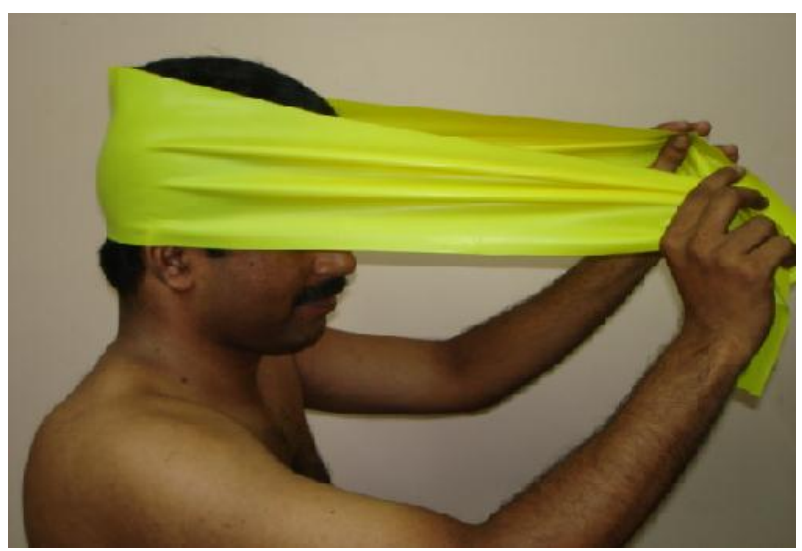




\section{CERVICAL SIDE FLEXION - LEFT}

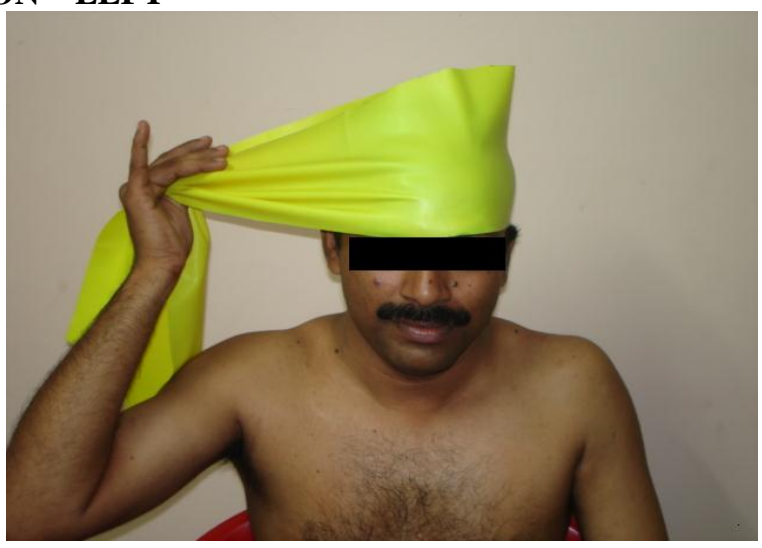

\section{CERVICAL ROTATION - RIGHT}

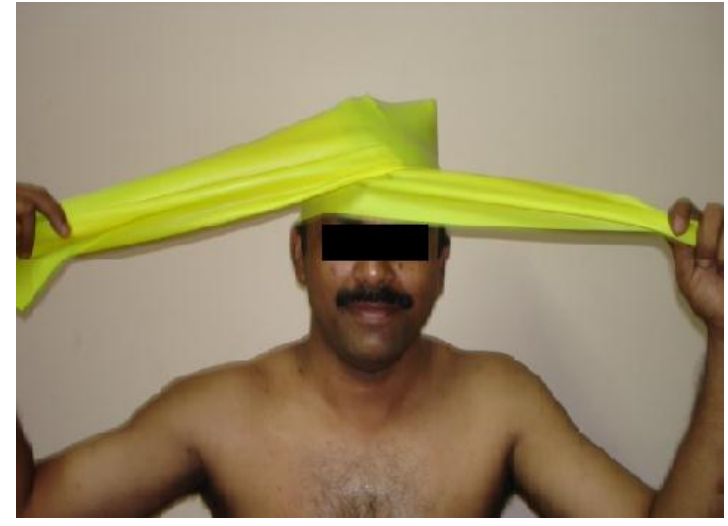

NECK DISABILITY INDEX (NDI):

\section{IV.Statistical Analysis}

\begin{tabular}{|c|c|c|c|}
\hline GROUP & MEAN \% & $\begin{array}{l}\text { STANDARD } \\
\text { DEVIATION }\end{array}$ & STANDARD ERROR MEAN \\
\hline Isometrics & 15.9000 & 7.3595 & 1.3437 \\
\hline Dynamics & 22.7333 & 10.0924 & 1.8426 \\
\hline
\end{tabular}

\begin{tabular}{|c|c|c|c|c|}
\hline GROUP & t-VALUE & $\begin{array}{ll}\text { DEGREE } & \text { OF } \\
\text { FREEDOM } & \end{array}$ & MEAN DIFFERENCE & p-VALUE \\
\hline $\begin{array}{l}\text { Isometrics } \\
\text { Vs } \\
\text { Dynamics }\end{array}$ & 2.996 & 58 & 6.83 & 0.004 \\
\hline
\end{tabular}

COMPARISON OF ISOMETBICSYSTERNAMICS USING NECK

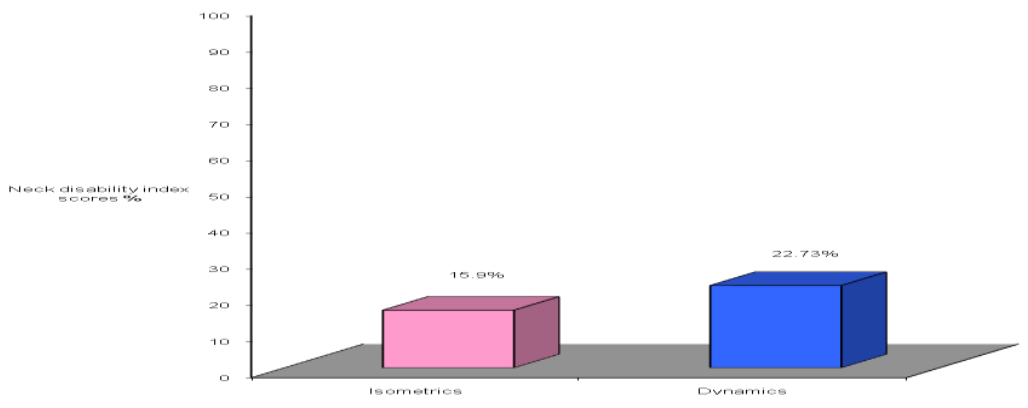

From the above tables we have arrived the mean, standard deviation and standard error mean for both isometric and dynamic groups. By using independent sample T-test, we have also arrived a highly significant difference 
$(\mathrm{p} \leq 0.05)$ at 0.05 level of significance. So we conclude that the group which has the higher mean (dynamics) is more effective in the treatment of chronic neck pain.

MANUAL MUSCLE TESTING (MMT):

\begin{tabular}{|c|c|c|c|}
\hline GROUP & MEAN & $\begin{array}{l}\text { STANDARD } \\
\text { DEVIATION }\end{array}$ & STANDARD ERROR MEAN \\
\hline Isometrics & 1.2667 & .7849 & .1433 \\
\hline Dynamics & 2.1333 & .7303 & .1333 \\
\hline
\end{tabular}

\begin{tabular}{|c|c|c|c|c|}
\hline GROUP & t-VALUE & $\begin{array}{l}\text { DEGREE } \\
\text { FREEDOM }\end{array}$ & OF & MEAN DIFFERENCE \\
\hline $\begin{array}{c}\text { Isometrics } \\
\begin{array}{c}\text { Vs } \\
\text { Dynamics }\end{array}\end{array}$ & 58 & 0.87 & 0.000 \\
\hline
\end{tabular}

COMPARISON OF ISOMETRICS YSSPYNAMICS USINO MANUAL

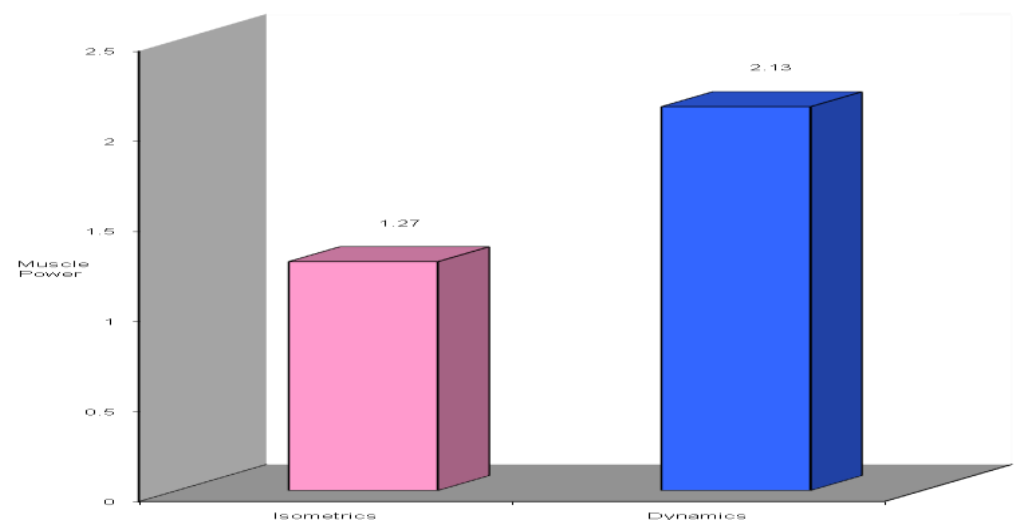

From the above tables we have arrived the mean, standard deviation and standard error mean for both isometric and dynamic groups. By using independent sample T-test, we have also arrived a highly significant difference $(\mathrm{p} \leq 0.05)$ at 0.05 level of significance. So we conclude that the group which has the higher mean (dynamics) is more effective in the treatment of chronic neck pain.

\section{Discussions}

This study shows that, participation in a three week neck strengthening program led to a considerable reduction in the average neck pain, disability and improvement of neck muscle power in the group of patient's who performed dynamic neck exercises. Randlov A et. al performed a study on "Intensive dynamic training for females with chronic neck/shoulder pain" showed that dynamic training program resulted in both subjective and objective improvements in patients suffering from chronic neck/shoulder pain ${ }^{36}$. In support to this, Berg HE et.al examine in their study whether dynamic neck resistance training could increase strength and reduce pain in workers with a high prevalence of neck disorders. As per the study dynamic neck strength training was given to the neck flexors, extensors and rotators on the basis of twelve minutes for a period of eight weeks. Results showed that this strength training increases the strength of rotators, extensors and flexors of neck. Also all individuals who had pain reported, reduced perceived neck pain after training ${ }^{5}$.

Although studies have proved that dynamic neck strength training increases the strength of the neck muscles and reduces neck pain, some of the studies like the one conducted by Portero et al proves that the beneficial effect of strength- training program (isometric resistance training) increases neck muscle size and strength during lateral flexion and decreases the fatigability of superficial muscles of the neck ${ }^{35}$. Whereas another study performed by Viljanen $\mathrm{M}$ et.al in "Effectiveness of dynamic muscle training, relaxation training or ordinary activity for chronic neck pain showed that the dynamic muscle training and relaxation training do not lead to better improvements in neck pain compared with ordinary activity ${ }^{46}$.

In favour of dynamic resistance program, some authors like Gary Kannen published in the chapter "Adaptations to exercise training" that either concentric or eccentric muscle contractions might be a part of the dynamic resistance exercise program. Concentric muscle contractions can offer very high forces and thus an appropriate overload stimulus. Eccentric contractions can actually produce more muscular force than that obtained during an isometric muscle contraction ${ }^{17}$. 
Carrie M Hall et.al also says that isometric exercise is commonly used to increase muscle performance. Although no joint movement occurs, isometric exercise is considered functional because it provides a strength base for dynamic exercise. They also say, dynamic exercise has the advantages that, there is increased movement of the joint, resulting in capsular, ligament and muscular flexibility and increased cartilage nutrition. Muscle strengthening occurs in all joint ranges achieved during the exercise and results in functionally more efficient muscle-joint complex ${ }^{8}$.

Apart from the fact that dynamic exercise has certain advantages than isometric exercise, some of the studies performed by Ylinen $\mathbf{J}$, Ruuska $\mathbf{J}$ proved that, isometric strength measurement is a useful and a practical method of objectively showing a functional improvement in response to rehabilitation ${ }^{49}$. A similar study performed by Jari Ylien et .al in "Active neck muscle training in the treatment of chronic neck pain in women" concluded that, both endurance training (dynamic neck exercises) and strength training (isometric neck exercises) were effective methods for decreasing the pain and disability in women with chronic, non specific neck pain ${ }^{24}$.

From my study, I have arrived a highly significant difference that is $(0.004 \leq 0.05$ in Neck Disability Index and $0.000 \leq 0.05$ in Manual Muscle Testing) at 0.05 level of significance. The graphical representation also shows that, the group that performed dynamic neck exercise has the higher mean value of $22.7 \%$ in Neck Disability Index and 2.1 in Manual Muscle Testing when compared to the isometric group which has only $15.9 \%$ in Neck Disability Index and 1.2 in Manual Muscle Testing. Based on the above results and obtained values, the null hypothesis can be rejected and the experimental hypothesis can be accepted and may be stated as, there will be a significant difference seen in dynamic neck exercises to isometric neck exercises in the treatment of chronic neck pain. Therefore dynamic neck exercise is a more effective method in the treatment of chronic neck pain.

\section{LIMITATIONS AND RECOMMENDATIONS LIMITATIONS:}

- Study is a short duration study.

- The intervals between the age group is more.

- Follow-up taken is inadequate.

\section{RECOMMENDATIONS:}

- This study can be performed on a larger sample size.

- It can be performed on homogenous population.

- The duration of the study can be more longer.

- The age group used for the study can be restricted.

- The follow-up period after the treatment can be adequate.

- Some other techniques or interventions can also be added along with strength and resistance training program.

\section{Conclusions}

Although both isometric neck exercises and dynamic neck exercises have been proven to be effective methods in reducing pain and disability in chronic neck pain patients, my study and the results that are obtained show us that, dynamic neck exercises has proved to be much more effective method than isometric neck exercises in the treatment of patients with chronic neck pain.

[1]. Aker PD, Gross AR, Goldsmith CH, Peloso P,Conservative management of mechanical neck pain; Systematic overview \& meta analysis ,BMJ 1996; 313:1291-1296.

[2]. Ann Thomson, Alison skinner, Joan Piercy, Tidy's Physiotherapy, $12^{\text {th }}$ edition, Mumbai, Varghese publishing house, 1996.

[3]. Aromaa A, Koskinen S, ed, Health and Functional Capacity in Finland; Baseline results of the health 2000 Health examination survey, Helsinki, Finland; National Public health Institute; 2002,Publication B3/2002,1023-1027.

[4]. Ayman Ali Gallom, Cervical spondylosis, e-Medicine, Department of Neurosurgery, University of Mississippi medical center-; October 26, 2005;200,1-11.

[5]. Berg HE, Berggren G, Tesch PA,Dynamic neck strength training effect on pain and function ,Arch Phys Med Rehab 1994; June 75(6); 661-5.

[6]. Brain R.Mulligan, Manual Therapy-NAGS, SNAGS, and MWMS etc, $5^{\text {th }}$ edition,New Zealand,Plane View Services, 1989.

[7]. Burnett AF, Naumanun FL, Price RS, Sanders RH.A comparison of training methods to increase neck muscle strength ,Work, 2005;25(3) 205-10.

[8]. Carrie M Hall, Lori Thein Brody-Therapeutic Exercise Moving towards Function, $2^{\text {nd }}$ edition, United kingdom,Zeefarm ltd,1980.

[9]. Carolyn Kisner MS, PT; Lymm Allen Colby MS PT-Therapeutic Exercise Foundations and Techniques, $3^{\text {rd }}$ edition,New delhi,Jaypee brothers, 1996. 
[10]. Cummings Gsand Tillman LJ, Currier, DP and Nelson RM, ADavies, Remodelling of dense connective tissue in normal adult tissues, Dynamics of Human Biological Tissues,BMJ, Philadelphia 1992;52:100-105.

[11]. David J.Magee, Orthopedic Physical Assessment, $4^{\text {th }}$ edition, Newdelhi, Harcourt (India) Pvt.Ltd,2002.

[12]. Davies, GJ; A Compendum of isokinetics in Clinical usage and Rehabilitation Techniques, Ed 2,WI,S\&S publishing a Crosse, 1985.

[13]. Devereuax MW, Neck pain, Prim Care 2004;31(1): 19-31.

[14]. Dvora shurman, Tel Aviv, Israel, Energetics-Working with Aging and the aged. Brain gym journal, March 2005;24:120-126.

[15]. Florence Peterson Kendall, Elizabeth Kendall Mc Corney Patricia Giece Provance, Muscle Testing and Function, $4^{\text {th }}$ edition,Noida UP, Gopsons, 1990 .

[16]. Fox E and Mathews D; The Physiological basis of Physical Education and Athletic.,ed 3, Philadelphia ,Saunders College Publishing, 1981.

[17]. Gary Kannen, Foundations of exercise science, Chapter 3-Adaptations to Exercise training, Edition 5,Ireland,Lipcon Itd services, 1986

[18]. Gross AR, Aker PD, Goldsmith CH.Peloso P,Conservative management of mechanical neck disorders; A systematic Overview and Meta analysis, Online Journal Curr Clin Trials,1996; July 30:Doc no: 200-201.

[19]. Harris \&Watkins, Adaptations to Strength Conditioning, $5^{\text {th }}$ edition,United kingdom,P\&P publishers, 1991.

[20]. Helen J.Histop, Daniel Worthinghams, Jacqueline Montgomery, Muscle Testing-Technique of Manual Examination, $7^{\text {th }}$ edition, Philadelphia, Harcourt Brace and Company, 1999.

[21]. Histop HJ: Quantitative Changes in Human Muscular Strength During Isometric Exercise, Phys Therapy,1963;43:21.

[22]. Howard Vernon, DC,The Neck Disability Index (NDI). An informal "blurb" from the author,Medline, 1991;45:32-35.

[23]. James E Graver, Barry A, Franklin,Resistance Training for Health and Rehabilitation, $5^{\text {th }}$ edition,Alabama,lippincott,1985.

[24]. Jari Ylinen MD, Esa-pekka Jakala MD, DMed Sc, Matti Nykanen MD, DMed Sc, Arja Hakkinen Phd; Esko Malkia Phd, Timo Pohjolainen MD, DMed Sc, Sirkka-lissa Karppi, MSc, Hannu Kautiainen, BA,Olavi Airaksinen MD, DMed Sc,Active Neck Muscle Training in Treatment of Chronic Neck Pain in Women-A Randomized Controlled Tria.,JAMA, May 21,2003-vol 289,no.19.

[25]. Jette AM et al, exercise-It's never too late: The Strong for Life Program. Am J Public Health:,1989; 89(1): 66-72.

[26]. KaschH, Bach FW, Stengaard-Pedersen, Jensen TS, Development in pain and neurological complaints after whiplash: a 1-year prospective study neurology,BMJ,2003, 60:743-749.

[27]. Lehmukuhl, LD and Smith, LK, Brunnstrom's Clinical Kinesiology, Ed 4, Philadelphia,F.A.Davis 1983.

[28]. Leon Chaetow,Advanced soft tissue technique muscle energy technique, $2^{\text {nd }}$ edition, New York,Churchill Livingstone,2001.

[29]. Mantyselka PT, Patient Pain in General Practice ed 6,Kuopio,Filnland ,Kuopio University publication,1998.

[30]. Mikesky AE ET al, Efficacy of a Home-based Training Program for Older Adults Using Elastic Tubing ,Europe J.Appl Physiol:1994; 69:316-320.

[31]. Orgeon K.Hunter,Article on Cervical Sprain and Strai,e Medicine,August 5,2005;48:305-308.

[32]. Phero JC ,Pharmacological Management of Head and Neck Pain-Otolaryngology Clin North Am,BMJ, 2003; 36(6): 1171-1185.

[33]. Pollock ML, Graves JE, Bannman MM, Legget SH, Carpenter DM, Carr C, Cirulli J, Matkozich J, Fulton M,frequency and Volume of Resistance Training: effect on Cervical Extension Strength, Arch Phys Med Rehab, 1993-oct: 74(10): 1080-6.

[34]. Pointer, Physical activity readiness Medical Examination for Pregnancy ,Medline,2002;109:25-28.

[35]. Portero P, Bigard AX, Gamet D ,Flageat JR, Guezennec CY, Effects of resistance training in humans on neck muscle performance , and electromyogram power spectrum changes, Eur J Appl Physiol , 2001 June , 84(6):540-6.

[36]. Randlov A, Ostergaard M, Manniche C, Kryger P, Jordan A, Heegaard S, Holm B,Intensive Dynamic Training for Females with Chronic neck/shoulder pain-a randomized controlled trail, [Clin Rehabil 1998 Jun, 12(3) 200-10.

[37]. Richard E Baxter,Pocket Guide to Musculoskeletal Assessment,Ed 4,United Kingdom,Burnett publishers,1982.

[38]. Rekola K,Health Services Utilization for Musculoskeletal Disorders in Finnish primary health care, Avta Univ, Pul Rehabil, 1993:D259: 53-59.

[39]. Rush PJ, Shore A, Physicians perceptions of the Value of Physical Modalities in the Treatment of Musculoskeletal Disease,Br.J.Rheumatol,1994, 33:566-568.

[40]. Susan B.O'Sullaivan. Thomas J.Schmitz-Physical Rehabilitation-Assessment and treatment, $4^{\text {th }}$ edition,New delhi,Jaypee Brothers medical Publishers (P)Ltd,2001 .

[41]. Sarig H Bahat,Evidence for Exercise Therapy in Mechanical Neck Disorders,Manual Therap,.Feb 2003,vol8, iss 1,pp10-20.

[42]. Shawn Kwak, DPT, Ryan NiederkleinDPT, ATC, Rebecca Tarcha, DPT, Cris Hughes, PT, Phd, OCS, cscs,Motin and Perceived Neck Disability in Community Dwelling Elderly Individuals,Journals of Geriatric Physical Therapy,1995; Vol 28: 2:05.

[43]. Thomas T.W, Chiui PhD, Tai-Hing Lam; MD, Anthony J.Hedly MD,A Randomized Controlled Trial on the Efficacy of Exercise for Patients with Chronic Neck Pain,Spine journal,2004; Volume 30,Number 1,ppE1-E7 ,Lippincott and Wilkins.Inc.

[44]. Topp,Theraband Instruction Manual, www.therabandacademy.com/research,2003;125:1140-1155 .

[45]. Topp.et al, The Effect of Dynamic versus Isometric resistance Training on pain and functioning about adults with Osteoarthritis of the knee, Arch Phys Med.Rehabil,2002 83:1187-1195.

[46]. Vilijanen M, Malmivaara A, Uitti J, Rinni M, Palmroos P, Laippala P,Effectiveness of Dynamic muscle training, relaxation training or ordinary activity for chronic neck pain: randomized controlled trial,BMJ.2003, Aug 30,327(7413): 475.

[47]. Vernon H, Mior S,The Neck Disability Index: A study of Reliability and Validity,J Manipulative Physiol Ther 1991(sep); 14(7); 409-415.

[48]. Watson Jones, Watson-Jones Fracture and Joint Injuries,Edition 6-Volume 2,Boston,Wilson Publishers, 1982.

[49]. Ylinen, Ruuska J,Clinical use of Neck Isometric Strength Measurement in Rehabilitation,Arch Phys Med Rehabil 1994 April;75(4): 465-9.

[50]. Zohn D, and Mannell J, Musculoskeletal Pain: Principles of Physical Diagnosis and Physical Treatment.Little Edition 4, Boston, Brown and Company, 1976. 